\title{
Appulau: Vertical Exchange pada Travel Wisata di Kepulauan Seribu
}

\author{
Puteri Ratnasari $^{1}$, Andi Susilo \\ ${ }^{1}$ Program Studi Ilmu Komputer, Fakultas Teknologi Informasi Universitas Respati Indonesia \\ ${ }^{2}$ Program Studi Teknologi Informasi, Fakultas Teknik, Universitas Darma Persada \\ Email: puteriratna44@gmail.com, andi.susilo@computer.org
}

\begin{abstract}
Abstrak
Penyedia layanan jasa wisata kepulauan seribu saat ini sangat beragam, mulai dari jenis paket yang ditawarkan sampai pada fasilitas yang disediakan dengan metode pembayaran hanya sebatas menggunakan uang tunai dan transfer bank saja, sehingga kami membangun aplikasi yang dinamakan Appulau sebuah Vertical Exchange berbasis aplikasi bergerak pada Travel Wisata di Kepulauan Seribu dapat menjadi platform multivendor bagi vendor yang memiliki layanan jasa wisata, serta menyediakan sistem pembayaran yang telah terintegrasi dengan payment gateway sehingga kemudahan, fleksibilitas, dan keamanan lebih terjamin
\end{abstract}

Kata kunci: Vertical Exchange, Mobile Application, Payment gateway

\section{Abstract}

Thousand islands tourism service providers are currently very diverse, ranging from the types of packages offered to the facilities provided with payment methods only using cash and bank transfers, so we built an application called Appulau, a Vertical Exchange based on mobile applications on Travel Tourism in the Thousand Islands can be a multivendor platform for vendors who have tour services, as well as providing a payment system that has been integrated with a payment gateway so that convenience, flexibility and security are guaranteed.

Keywords: Vertical Exchange, Mobile Application, Payment gateway

\section{PENDAHULUAN}

Kepulauan Seribu merupakan suatu kepulauan yang terletak di DKI Jakarta, dimana terdapat banyak pulau didalamnya yang menjadi tujuan wisata baik itu wisatawan lokal maupun mancanegara. Kepulauan Seribu masuk ke dalam 10 Destinasi Pariwisata Prioritas dalam Pembangunan Destinasi Pariwisata Prioritas Tahun 2016-2019 oleh Kementerian Pariwisata.

Kepulauan Seribu merupakan pulau wisata yang didalamnya terdapat pulau pulau permukiman yang dijadikan sebagai objek wisata dan banyak diminati oleh wisatawan lokal maupun mancanegara, pulau pulau yang paling banyak dikunjungi oleh wisatawan

http://ejournal.urindo.ac.id/index.php/TI yaitu Pulau Tidung, Pulau Pari, Pulau Harapan, Pulau Untung Jawa, Pulau Pramuka.

Penyedia layanan jasa wisata kepulauan seribu saat ini sangat beragam, mulai dari jenis paket yang ditawarkan sampai pada fasilitas yang disediakan. Dari keberagaman tersebut membuat pelanggan memiliki banyak pilihan untuk menjadi bahan pertimbangan dalam melakukan perencanaan perjalanan wisata menuju kepulauan seribu, namun dengan keberagaman tersebut dapat membuat pelanggan atau wisatawan membutuhkan waktu yang lebih lama dalam mencari paket wisata yang sesuai kebutuhan ketika harus membandingkan antara penyedia layanan jasa wisata satu dengan yang lain karena perlu membuka satu persatu alamat website 
yang telah dibuat oleh penyedia layanan jasa wisata tersebut

Perbandingan metode pemesanan dan pembayaran serta platform yang digunakan (gambar 1) didapatkan dari hasil pencarian di Internet yang merupakan alamat situs web dengan Search Engine Optimization (SEO) teratas dan telah banyak di gunakan oleh wisatawan dalam melakukan perjalanan wisata Kepulauan Seribu.

Dalam proses pemesanan paket wisata yang di tawarkan penyedia layanan jasa wisata saat ini memang telah ada beberapa yang terlihat sudah cukup baik dan lengkap dengan adanya itenary dan harga paket yang telah ditawarkan, setelah itu pada proses pemesanan paket wisata penyedia layanan jasa wisata yang telah menggunakan formulir secara daring seperti pada alamat situs https://dinotraveling.com/, namun masih ditemukan cara yang manual yaitu pelanggan diharuskan mengentri sendiri harga yang sesuai dengan paket wisata yang dipilih, hal tersebut cukup merepotkan karena pelanggan harus mengingat harga yang ditawarkan pada halaman lain sebelum melakukan pemesanan.

Dari sisi pembayaran bahwa lebih dominan dilakukan pelunasan pembayaran secara tunai meskipun bisa melalui rekening bank namun cara seperti itu dirasa kurang memberikan rasa aman jika dilihat dari sisi pelanggan selain itu transfer antar bank cukup merepotkan jika pelanggan tidak memiliki mobile banking maka harus menuju gerai ATM yang tersedia di sekitar wilayah nya, hal tersebut dapat mempengaruhi keputusan pelanggan dalam melakukan pemesanan paket wisata.

Setelah dilihat dari kondisi yang ada saat ini, maka aplikasi Vertical Exchange berbasis mobile Travel Wisata di Kepulauan Seribu dapat memberikan solusi dan kemudahan bagi pelanggan dalam membandingkan antara website satu dengan yang lainnya juga memberikan kemudahan dalam pemesanan untuk melakukan perencanaan wisata ke kepulauan seribu sampai pada pembayaran yang dapat dilakukan tanpa harus membawa uang tunai juga mencari gerai-gerai atm yang cukup merepotkan, selain itu jika dilihat dari sisi penyedia layanan jasa wisata diharapkan dapat lebih mudah untuk mendapatkan pelanggan atau wisatawan.
Berdasarkan kondisi yang terjadi saat ini, terdapat beberapa masalah yang ditemukan sebagai berikut :

1. Saat ini pemilik travel wisata memiliki website secara pribadi dan belum adanya platform yang dapat menampung website - website yang telah tersedia.

2. Masih terdapat penyedia layanan jasa wisata yang belum menyediakan proses pemesanan secara online yaitu pemesanan hanya sebatas kirim pesan dan via telephone

3. Pemesanan secara online yang telah ada masih mengharuskan pelanggan menginput harga secara manual.

4. Metode pembayaran hanya sebatas tunai dan transfer antar bank saja

5. Platform yang digunakan hanya berbasis web.

Dari pembahasan mengenai identifikasi masalah yang ada, agar tidak meluas dan diluar dari pembahasan yang ada, sehingga dapat sesuai dengan keinginan dan harapan maka ruang lingkup meliputi:

1. jenis transaksi yang digunakan yaitu B2B (Business to Business)

2. Membuat formulir pemesanan online dan disertakan dengan harga yang ditampilkan secara otomatis berbasis online setelah pelanggan melakukan pemesanan sesuai dengan paket yang dipilih didalam aplikasi.

3. Pada proses transaksi pembayaran, digunakan pihak ketiga yaitu payment gateway.

Adapun tujuan dari penilitian ini adalah untuk membangun vertical exchange mobile application travel wisata kepulauan seribu, yang menggunakan jenis transaksi B2B (Business to Business) yang menyediakan formulir pemesanan dan transaksi pembayaran dilakukan secara online.

Adapun manfaat dari pembuatan Vertical Exchange pada travel wisata di Kepulauan Seribu yaitu

1. Untuk menyediakan platform bagi pemilik website yang telah ada agar dapat saling menjual layanan yang mereka miliki. 
2. Untuk mempermudah pelanggan dalam membandingkan harga serta fasilitas antara satu website dengan website lainnya.

3. Mempermudah pelanggan pada saat reservasi, karena formulir pemesanan dibuat dengan dilengkapi biaya yang otomatis ditampilkan ketika pelanggan melakukan pemesanan

4. Mempermudah pelanggan dalam melakukan transaksi pembayaran, karena pembayaran dapat dilakukan dengan metode pembayaran digital.

\section{METODE}

Saat ini pemilik travel wisata kepulauan seribu memiliki website yang di pergunakan sebagai media promosi untuk mencari pelanggan atau wisatawan yang ingin melakukan perjalanan wisata ke pulau pulau yang ada di kepulauan seribu, website yang telah ada dirasa belum cukup kompleks seperti dalam proses pemesanan masih ada yang menyediakan cara manual seperti pemesanan melalui chat pribadi yang dilakukan antara penyedia layanan jasa wisata dengan pelanggan, hal tersebut cukup merepotkan apabila ada banyak nya pelanggan yang bertanya atau melakukan pemesanan dalam waktu yang bersamaan, jika terlalu lama merespon maka tidak menutup kemungkinan bisa membuat pelanggan berubah fikiran, menunda bahkan membatalkan untuk memesan paket wisata pada travel tersebut.

Metode pembayaran yang ada saat ini hanya sebatas uang tunai dan transfer bank saja, yang seharusnya bisa di tambahkan dengan metode pembayaran lain seperti penggunaan digital payment yang memang telah menjadi pilihan bagi banyak orang dalam melakukan transksi pembayaran.

\subsection{Analisis Kebutuhan Preangkat Lunak}

Analisis perangkat lunak terdiri dari spesifikasi minimum perangkat lunak yang dipakai dalam membangun dan mengimplementasikan mobile application ini, yaitu :

a. Sistem Operasi Windows 10 Pro

http://ejournal.urindo.ac.id/index.php/TI
b. Aplikasi IDE Eclipse
c. SDK 19.0 Android 4.4
d. Visual Studio Code

\subsection{Analisis Kebutuhan Preangkat Keras}

1. Perangkat Keras Aplikasi Backend

- $\quad$ Processor: Kapasitas Minimum 2.0 GHZ

- Memori: Minimum $512 \mathrm{MB}$

- VGA: Kecepatan Minimum 32 MB

- Hardisk: Minimum Kapasitas 20 GB

2. Perangkat keras Aplikasi Frontend

- Resolusi: 240 x 320 pixels

- Memori: $100 \mathrm{MB}$

- CPU: $300 \mathrm{MHZ}$

\subsection{Pemodelan Sistem}

Pemodelan sistem pada perancangan mobile application menggunakan Unified Modeling Language (UML), antara lain meliputi :

1. Activity diagram

2. Use case diagram

3. Sequence diagram

\subsubsection{Activity Diagram}

Berikut Activity Diagram mobile aplikasi appulau yang telah dibuat pada gambar . 


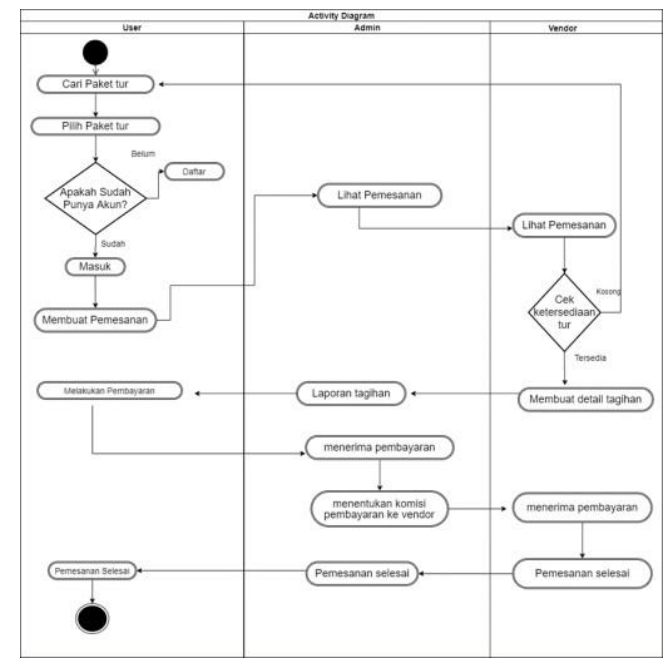

Gambar 1 Activity Diagram

\subsubsection{Use Case Diagram}

Use Case Diagram mendeskripsikan sebuah interaksi antara satu atau lebih aktor dengan sistem informasi yang akan dibuat. Use Case Diagram dapat dilihat pada gambar .

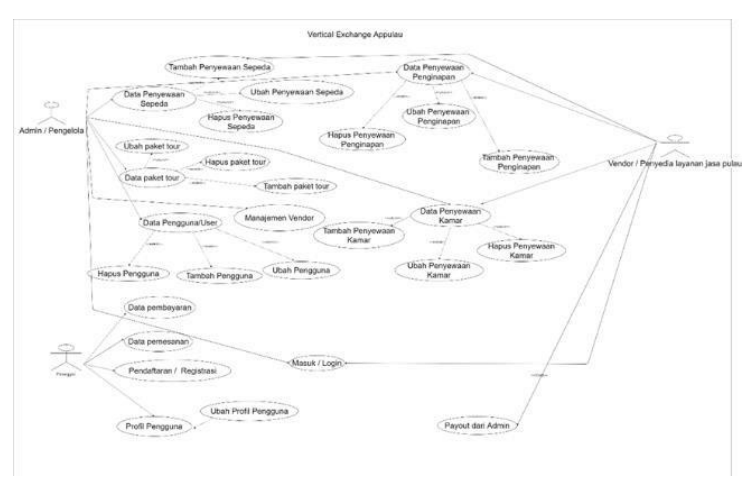

Gambar 2. Use Case Diagram

\subsubsection{Sequence Diagram}

1. Sequence Diagram Login Admin
Sequence Diagram Login Admin merupakan proses login yang dilakukan oleh Admin, dapat dilihat pada gambar .

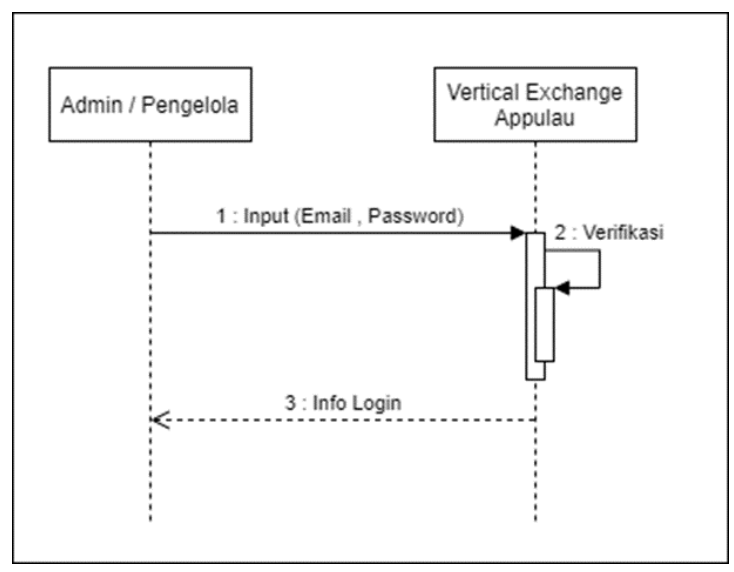

Gambar 3 Sequence Diagram Login Admin

2. Sequence Diagram Login Pelanggan

Sequence Diagram Login Pelanggan merupakan proses login yang dilakukan oleh Pelanggan, dapat dilihat pada gambar 4 .

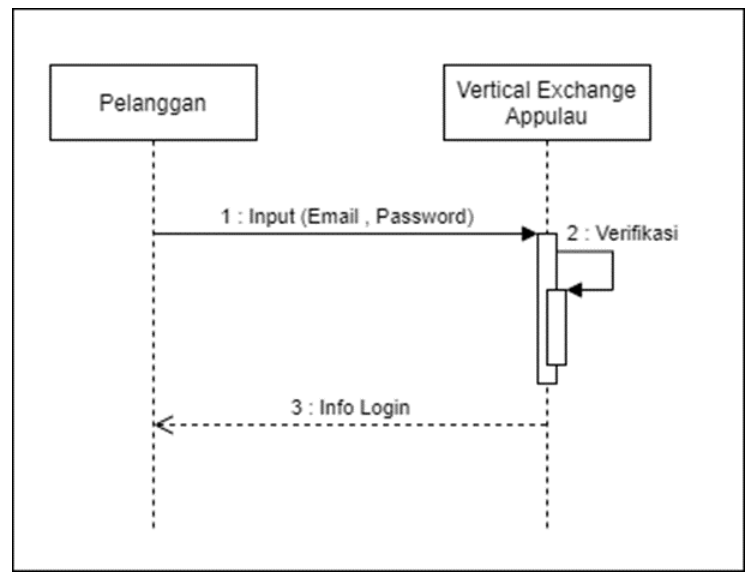

Gambar 4 Sequence Diagram Login Pelanggan 
Sequence Diagram Login Vendor merupakan proses login yang dilakukan oleh Vendor, dapat dilihat pada gambar .

Gambar 5 Sequence Diagram Login Vendor

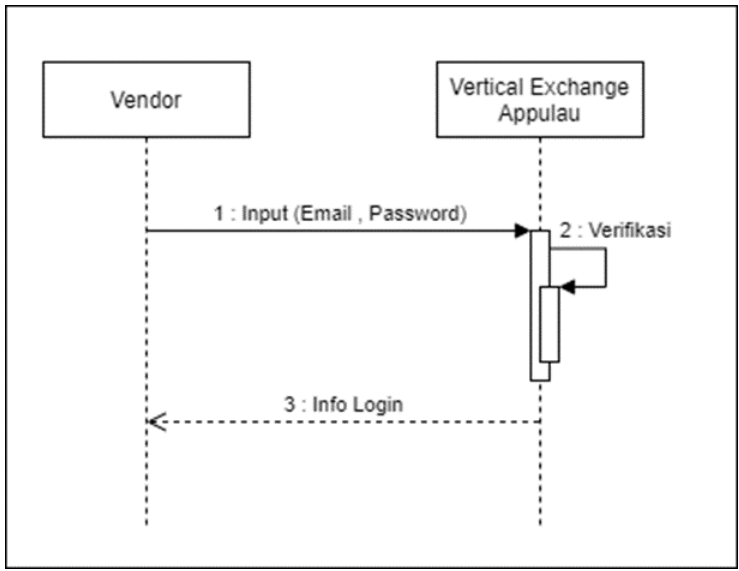

HASIL

\subsection{Rancangan Fisik User Interface}

Rancangan fisik user interface menampilkan beberapa halaman dari implementasi mobile application yang sudah jadi dan siap digunakan. Hasil dari implementasi disajikan dalam bentuk screenshoot berupa gambar pada beberapa halaman. Dalam penjelasannya, sistem akan dibedakan menjadi dua yaitu penjelasan dari Administrator dan customer serta vendor. Berikut ini adalah tampilan dari masing - masing pihak yang termasuk dalam sistem implementasi mobile application

\section{Tampilan halaman utama}

Tampilan halaman utama merupakan tampilan yang pertama kali muncul ketika aplikasi diakses. Tampilan halaman utama dapat dilihat pada gambar

http://ejournal.urindo.ac.id/index.php/TI

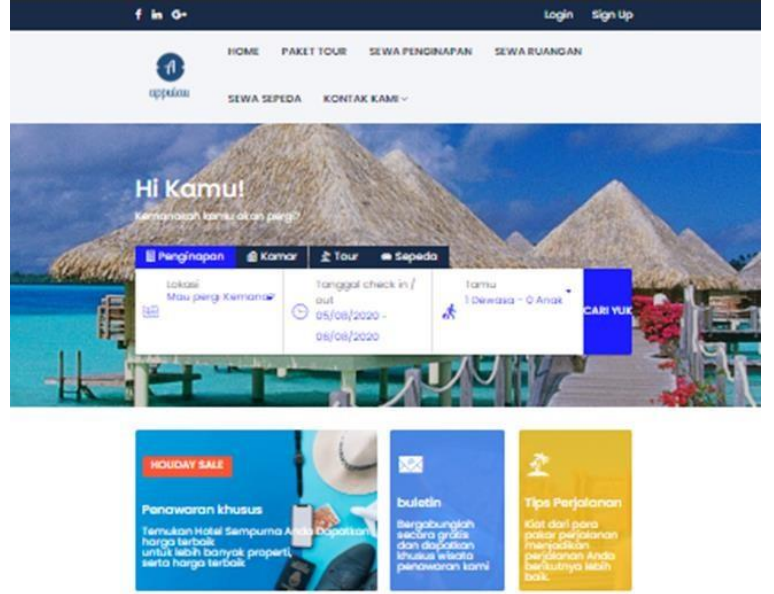

Gambar 6 Tampilan halaman utama pada Admin

5. Tampilan login

Tampilan halaman login berfungsi untuk melakukan login sistem bagi Admin, user, dan vendor dengan cara input username dan password pada kotak login pada halaman login. Tampilan halaman login dapat dilihat pada gambar .

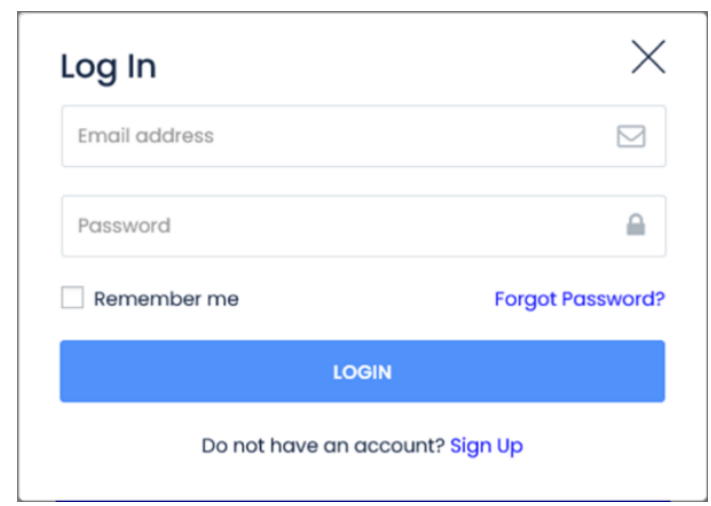

Gambar 7 Tampilan halaman login pada Admin, user, vendor

\section{Tampilan halaman Admin Dashboard}

Halaman admin dashboard merupakan sebuah tampilan yang dibuat dengan tujuan sebagai halaman dashboard admin dimana admin dapat melakukan check dan administrasi pada setiap transaksi. 
Tampilan halaman Admin Dashboard Home dapat dilihat pada gambar 9 .

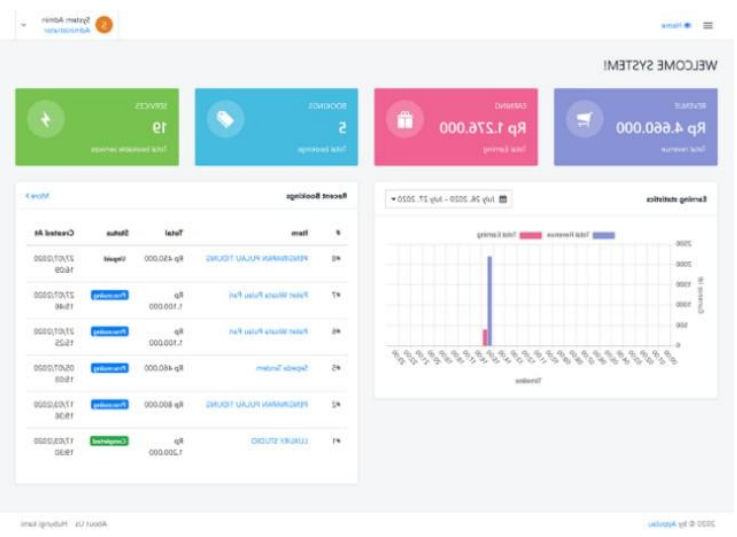

Gambar 8 Tampilan halaman Admin Dashboard Home

\section{Tampilan Halaman Vendor Dashboard}

Halaman vendor dashboard merupakan sebuah halaman yang dibuat dengan tujuan sebagai halaman dashboard vendor dimana vendor bisa manage layanan wisata.
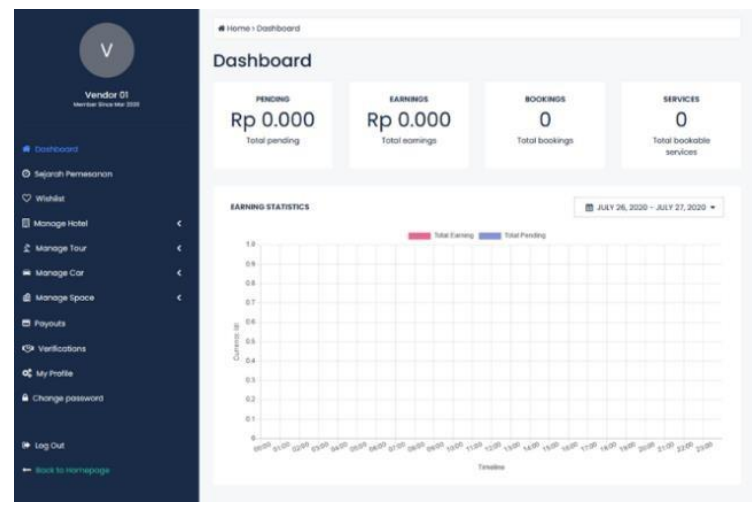

Gambar 9 Tampilan halaman vendor dashboard

\section{KESIMPULAN}

1. Aplikasi yang dibuat yaitu sebuah platform multivendor berbasis web dan mobile.

2. Dengan Appulau Metode pemesanan paket wisata di kepulauan Seribu lebih terintegrasi dan aman.
3. Pemilik travel wisata yang ada di kepulauan seribu dapat bergabung menjadi vendor dari Appulau.

4. Metode pembayaran melibatkan pihak ketiga agar pilihan pembayaran lebih fleksibel.

\section{DAFTAR PUSTAKA}

1. Afrina, Mira. (2016) "Pengembangan Sistem Informasi Pariwisata Kota Palembang Berbasis Mobile Android "Jurnal Sistem Informasi (JSI), Vol. 8, No. 2, ISSN Online: 2355-4614. Universitas Sriwijaya. Diakses tanggal 25 Juli 2020.

2. Havuluddin. (2016) "Memahami Penggunaan UML (Unified Modelling Language)" Jurnal Informatika Mulawarman. Vol. 6, No.1, ISSN 2597-4963.Jurnal ilmiah ilmu komputer. Diakses tanggal 3 Agustus 2020.

3. Marco,Robert. (2017) "Analisis Sistem Informasi E-Marketplace Pada Usaha Kecil Menengah (UKM) Kerajinan Bambu Dusun Brajan "Jurnal Ilmiah DASI Vol. 18. No. 2 (p. 48-

4. Afrina, Mira. (2016) "Pengembangan Sistem Informasi Pariwisata Kota Palembang Berbasis Mobile Android "Jurnal Sistem Informasi (JSI), Vol. 8, No. 2, ISSN Online: 2355-4614. Universitas Sriwijaya. Diakses tanggal 25 Juli 2020.

5. Havuluddin. (2016) "Memahami Penggunaan UML (Unified Modelling Language)" Jurnal Informatika Mulawarman. Vol. 6, No.1, ISSN 2597-4963.Jurnal ilmiah ilmu komputer. Diakses tanggal 3 Agustus 2020.

6. Marco,Robert. (2017) “Analisis Sistem Informasi E-Marketplace Pada Usaha Kecil Menengah (UKM) Kerajinan Bambu Dusun Brajan “Jurnal Ilmiah DASI Vol. 18. No. 2 (p. 48- 
Jurnal Teknologi Informasi, Vol 6 No 2 Desember 2020

E-ISSN :2623-1700

P-ISSN : 1693-3672 
Jurnal Teknologi Informasi, Vol 6 No 2 Desember 2020

E-ISSN :2623-1700

P-ISSN : 1693-3672 